\title{
Report of a pregnant woman with mosaic Turner syndrome
}

\author{
1Yunus Emre TOPDAĞI \\ 2Seray KAYA TOPDAĞI \\ (D) ${ }^{3}$ Emsal Pınar TOPDAĞI YILMAZ \\ (D) ${ }^{1}$ Ali İrfan GÜZEL
}

1'Department of Gynecology and Obstetrics, Sanko University Faculty of Medicine, Gaziantep, Turkey

${ }^{2}$ Department of Gynecology and Obstetrics, Abdulkadir Yüksel State Hospital, Gaziantep, Turkey

${ }^{3}$ Department of Gynecology and Obstetrics, Atatürk University Faculty of Medicine, Erzurum, Turkey

\section{ORCID ID}

YET : 0000-0003-0656-0765

SKT : 0000-0001-6293-478X

EPTY: 0000-0001-8593-5726

AiG : 0000-0002-9518-3772

\begin{abstract}
Spontaneous pregnancy in women with Turner syndrome is rare (5\%) and relatively high risk. A number of methods to preserve fertility in such women have been discussed. Careful follow-up is required during these pregnancies due to the high incidence rates of neonatal, obstetric, maternal, and cardiovascular complications. A 39-year-old multigravid woman (G5, P3, A2) with mosaic Turner syndrome with a history of three spontaneous pregnancies and two miscarriages was evaluated at our clinic. The analysis showed mos 45,X [9]/46,XX [38] mosaic Turner syndrome. Her first and fourth pregnancies resulted in miscarriages during the first trimester. Here, we discuss a pregnant woman with mosaic Turner syndrome with unaffected fertility but with a history of spontaneous pregnancies/miscarriages, with reference to the current literature.
\end{abstract}

Keywords: Mosaic turner syndrome, spontaneous pregnancy, turner syndrome.

Cite this article as: Topdağı YE, Kaya Topdağı S, Topdağı Yılmaz EP, Güzel Ail. Report of a pregnant woman with mosaic Turner syndrome. Zeynep Kamil Med J 2021;52(1):46-48.

Received: September 18, 2020 Accepted: February 28, $2021 \quad$ Online: March 31, 2021

Correspondence: Yunus Emre TOPDAĞI, MD. Sanko Üniversitesi Tıp Fakültesi, Kadın Hastalıkları ve Doğum Anabilim Dalı, Gaziantep, Turkey. Tel: +90 5358234656 e-mail: emretopdagi@ hotmail.com

(c) Copyright 2021 by Zeynep Kamil Medical Journal - Available online at www.zeynepkamilmedj.com 


\section{INTRODUCTION}

Turner syndrome is characterized by the absence of all or part of a normal second sex chromosome in females, ${ }^{[1]}$ which often leads to a constellation of physical findings, including congenital lymphoedema, short stature, and gonadal dysgenesis. ${ }^{[2]}$ Turner syndrome has an incidence of 1 in 2500 live births and is one of the most common chromosomal abnormalities worldwide. ${ }^{[3,4]}$ The majority of patients have a short stature, infertility, and absence of secondary sex characteristics. The classic form of Turner syndrome is associated with a $45, X$ karyotype, accounting for approximately half of all cases. The mosaic form $(45, X / 46, X X)$ accounts for $15-25 \%$ of Turner syndrome cases, while the remaining cases have structural abnormalities in the $\mathrm{X}$ chromosome..$^{[5]}$ The syndrome is caused by partial or complete loss of one of the $X$ chromosomes, which leads to haploinsufficiency of genes involved in the development or maintenance of ovarian reserve. Approximately $1-2 \%$ of women with Turner syndrome can become pregnant naturally. Several studies have reported that the rates of spontaneous pubertal development and menarche, as well as unassisted pregnancy, are greater in Turner syndrome with mosaicism than in monosomy $X$ patients. ${ }^{[6]}$ Here, we report a 39-year-old woman with 45,X [9]/46,XX [38] Turner syndrome mosaicism who had spontaneous puberty and a history of three spontaneous pregnancies and two miscarriages. The incidence of, and prognostic counseling topics for, spontaneous adolescence, menarche, and fertility is discussed in relation to this case and the current literature.

\section{CASE REPORT}

A 39-year-old multigravid woman (G5, P3, A2) with mosaic Turner syndrome who had a history of three spontaneous pregnancies and two miscarriages was evaluated at our clinic. The patient's parents appeared healthy and were of normal height and weight. There was no history of hereditary or congenital disease in the family. There was no special follow-up. She had achieved normal developmental milestones and spontaneous puberty with regular menses. She was not using contraception. Here height and weight were $150 \mathrm{~cm}$ and $65 \mathrm{~kg}$, respectively, indicating a body mass index of 28.9. The first clinical finding that led to karyotype analysis was a growth rate limitation at the age of 18 years. Cytogenetic analysis of blood lymphocytes revealed a karyotype of Turner syndrome mosaicism with $45, X$ (9 cells)/46,XX (38 cells). The analysis showed mos 45,X [9]/46, XX [38] mosaic Turner syndrome (Fig. 1). Echocardiography showed a normal aorta and aortic valve. Ophthalmologic examination and audiography were normal. The patient's initial echocardiography did not show any cardiovascular malformations associated with Turner syndrome, including normal thoracic aortic dimensions (aortic size index $2.0 \mathrm{~cm} / \mathrm{m}^{2}$ ) without coarctation symptoms. The patient was followed up from gestational week 25 of her pregnancy to delivery.

Arterial blood pressure was monitored regularly throughout the course of pregnancy and found to be normal, ranging between $110 / 70 \mathrm{mmHg}$ and $120 / 80 \mathrm{mmHg}$. Typical blood screening tests (cytomegalovirus, rubella, Toxoplasma gondii antibodies, total blood cell count, blood biochemistry, thyroid function, and hemoglobin electrophoresis), a glucose tolerance test, urinalysis, general urine culture, and antenatal ultrasonography were all normal. She had a history of three spontaneous pregnancies and two miscarriages. Her first and

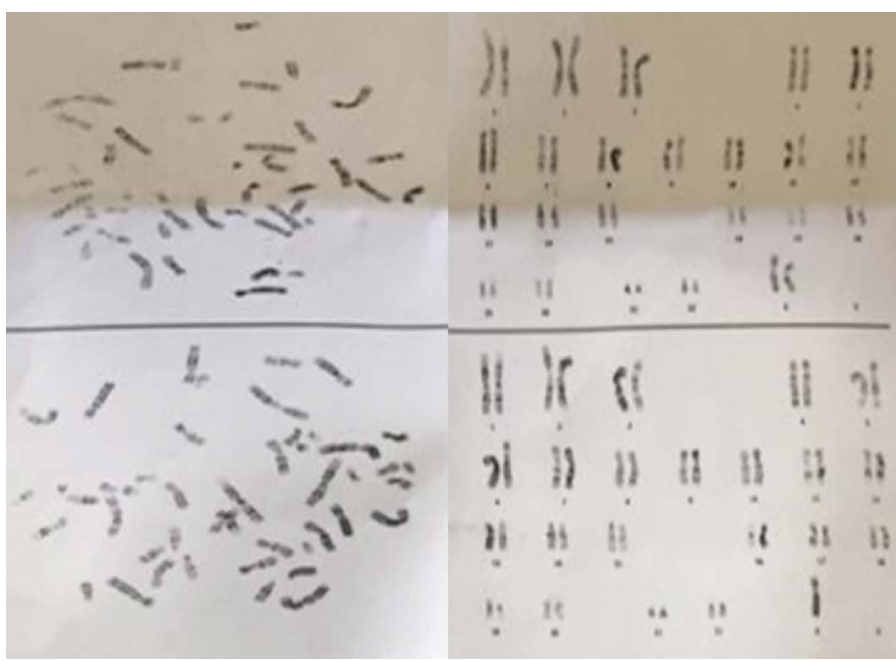

Figure 1: The cytogenetic analysis report of mos 45, X [9]/46,XX [38] mosaic Turner syndrome.

fourth pregnancies resulted in miscarriages during the first trimester, while the second and third pregnancies resulted in live births by cesarean section. The patient gave birth to a normal healthy $3550 \mathrm{~g}$ live baby girl at gestational week 38 .

\section{DISCUSSION}

Turner syndrome is a chromosomal abnormality caused by complete or partial loss of one $X$ chromosome and is usually characterized clinically by a short stature and primary ovarian failure. Classical Turner syndrome is the result of complete loss of an $X$ chromosome in all cells, resulting in a 45,X karyotype, and accounts for half of all cases. The most common karyotype in mosaic Turner syndrome is $45, X / 46, X X$, which accounts for approximately $15-25 \%$ of cases. ${ }^{[7]}$ Jacobs et al. ${ }^{[8]}$ reported that among 84 cases of Turner syndrome with a standard karyotype $(45, X), 16 \%$ had mosaicism with a second cell type containing a ring $X$ chromosome $(45, X / 46, X, r(X))$. Later, adolescence, even during menstrual cycle and women with menstrual cycle, even deterioration and only $2-8 \%$ of spontaneous pregnancy. Most of these pregnancies (87-92\%) occur in women with mosaicism. ${ }^{[6,9]}$

In a previous study of 1648 women with Turner syndrome, 86 women achieved spontaneous conception (5.2\%), 128 live infants were delivered, and most patients $(76.7 \%)$ presented with the $45, X / 46, X X$ karyotype. ${ }^{[6]}$ The frequency of spontaneous pregnancy ranged from $1.26 \%$ to $5.6 \%$. With regard to gestational outcome, an expressive number of children born, and abortions were observed, the latter with values of $54.9 \%$ and $34.6 \%$. In another study, 62 Turner syndrome patients achieved spontaneous pregnancy, with a total of 153 pregnancies. Most patients in this cohort had the $45, X / 46, X X$ karyotype (42 patients). The minimum and maximum ages at pregnancy were 21 and 32 years, respectively. ${ }^{[10]}$ The present study evaluated patients with Turner syndrome and spontaneous pregnancy with mosaic (more frequent) and pure karyotype. ${ }^{[6,9-12]}$

In a few studies, it is believed that the rate of spontaneous pregnancy in Turner syndrome was underestimated because many individuals with Turner syndrome are not diagnosed due to the wide phenotypic variability associated with this chromosomal abnormality. 
Therefore, diagnosis is difficult in those without significant dysmorphism. Thus, many affected individuals may have spontaneous pregnancies, and a cytogenetic diagnosis cannot be made or is delayed. On the other hand, a previous study described a Turner syndrome patient with the $45, X / 47, X X X$ karyotype who had five miscarriages by the age of 26 years old; the first, third, fourth, fifth, and sixth pregnancies resulted in miscarriages during the first trimester. Her second pregnancy resulted in the birth of a healthy girl with karyotype 46,XX. The $45, X / 47, X X X$ karyotype is rare, accounting for only $1.5 \%$ of Turner syndrome patients. ${ }^{[13]}$

Spontaneous pregnancies are rare, and recurrent pregnancy even rarer, in women with Turner syndrome. ${ }^{[14]}$ Considering the chance of spontaneous pregnancy, even in mosaic cases, protection of fertility by oocyte vitrification and/or ovarian tissue freezing should be discussed at a relatively young age, preferably immediately after pubertal development (age 13-15 years), when the ovaries are still functional. Therefore, a number of methods for preserving fertility in such cases have been discussed. Careful follow-up is required during these pregnancies due to the high incidence of neonatal, obstetric, maternal, and cardiovascular complications. Regardless of the type of pregnancy, all pregnancies in women with Turner syndrome should be considered high risk and should be monitored closely for obstetric complications. It is recommended that a multidisciplinary team composed of specialists in the fields of maternal-fetal medicine, cardiology, and endocrinology closely monitor Turner syndrome patients during pregnancy due to risks of worsening cardiovascular diseases during pregnancy and specific complications. However, there are very few reports on spontaneous pregnancy in Turner syndrome, and therefore, more research is needed to clarify the true frequency of spontaneous conception in such women. In addition to rigorous neonatal follow-up, the team should provide assistance to patients who wish to continue to conceive, before they become pregnant, to provide comprehensive risk assessment and genetic consultation. ${ }^{[15]}$

\section{CONCLUSION}

We present a woman with Turner syndrome with a history of spontaneous pregnancies and live births and discussed our observations in relation to the current literature.

\section{Statement}

Informed Consent: Written informed consent was obtained from patients who participated in this study.

Peer-review: Externally peer-reviewed.

Author Contributions: Concept - YET, SKT; Design - YET, AiG; Supervision - SKT, EPTY; Resource - YET, AIG; Materials - YET, EPTY; Data Collection and/or Processing - SKT, EPTY; Analysis and/or Interpretation - YET, AIG; Literature Search - YET, EPTY; Writing - YET, SKT; Critical Reviews - YET, AIG.
Conflict of Interest: The authors have no conflict of interest to declare.

Financial Disclosure: The authors declared that this study has received no financial support.

\section{REFERENCES}

1. Nussbaum RL. Thompson and Thompson Genetics in Medicine. 6th ed. WB Saunders Company; 2001. p. 172-5.

2. Noor M, Abdullah S, Mahmood S. Turner's syndrome. Gomal J Med Sci 2007;5:33-7.

3. Güneş $S$, Kara N, Sürücü B, et al. Two turner syndrome patients with the mosaic 45, X/46, X,I (Xq) Karyotipe: Case report. Turk Klin J Med Sci 2008;28:236-8.

4. Soenger P. Turner's syndrome. N Engl J Med 1996;335:1749-54.

5. Melmed S, Koenig R, Rosen C, Auchus R, Goldfine A. Disorders of sex development. In: William's Textbook of Endocrinology. Philadelphia, PA: Saunders; 2008. p. 783-848.

6. Bryman I, Sylven L, Berntorp K, Innala E, Bergström I, Hanson C, et al. Pregnancy rate and outcome in Swedish women with Turner syndrome. Fertil Steril 2011;95(8):2507-10.

7. Rapaport R. Hypofunction of the ovaries. In: Kliegman RM, Behrman RE, Jenson HB, Stanton BF, editors. Nelson Textbook of Pediatrics. 18th ed. Philadephia, PA: Saunders; 2008. p. 2316-40.

8. Jacobs $\mathrm{P}$, Dalton $\mathrm{P}$, James $\mathrm{R}$, Mosse $\mathrm{K}$, Power M, Robinson D, et al. Turner syndrome: A cytogenetic and molecular study. Ann Hum Genet 1997;61(6):471-83.

9. Hadnott TN, Gould HN, Gharib AM, Bondy CA. Outcomes of spontaneous and assisted pregnancies in Turner syndrome: The US national institutes of health experience. Fertil Steril 2011;95(7):2251-6.

10. Doğer E, Çakıroğlu Y, Ceylan Y, Ulak E, Özdamar O, Çalışkan E. Reproductive and obstetric outcomes in mosaic Turner's syndrome: A cross-sectional study and review of the literature. Reprod Biol Endocrinol 2015;13:59.

11. Bernard V, Donadille B, Zenaty D, Courtillot C, Salenave S, de la Perrière $A B$, et al. Spontaneous fertility and pregnancy outcomes amongst 480 women with Turner syndrome. Hum Reprod 2016;31(4):782-8.

12. Birkebaek NH, Crüger D, Hansen J, Nielsen J, Bruun-Petersen G. Fertility and pregnancy outcome in Danish women with Turner syndrome. Clin Genet 2002;61(1):35-9.

13. Sahinturk S, Sag SO, Ture M, Gorukmez O, Topak A, Yakut T, et al. A fertile patient with 45X/47XXX mosaicism. Genet Couns 2015;26(1):29-34.

14. Alves C, Silva SF. Spontaneous procreation in Turner syndrome: Report of two pregnancies in the same patient. Syst Biol Reprod Med 2012;58(2):113-5.

15. Vieira CA, Fontenele EG, Albuquerque AM, Quezado R. Síndrome de Turner desfecho de uma gestação spontânea. Rev Med UFC 2017;57(2):69-72. 